\title{
Do improvements in outreach, clinical, and family and community-based services predict improvements in child survival? An analysis of serial cross-sectional national surveys
}

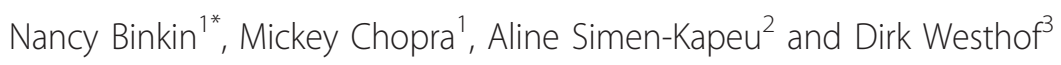

\begin{abstract}
Background: There are three main service delivery channels: clinical services, outreach, and family and community. To determine which delivery channels are associated with the greatest reductions in under- 5 mortality rates (U5MR), we used data from sequential population-based surveys to examine the correlation between changes in coverage of clinical, outreach, and family and community services and in U5MR for 27 high-burden countries.

Methods: Household survey data were abstracted from serial surveys in 27 countries. Average annual changes (AAC) between the most recent and penultimate survey were calculated for under-five mortality rates and for 22 variables in the domains of clinical, outreach, and family- and community-based services. For all 27 countries and a subset of 19 African countries, we conducted principal component analysis to reduce the variables into a few components in each domain and applied linear regression to assess the correlation between changes in the principal components and changes in under-five mortality rates after controlling for multiple potential confounding factors.

Results: AAC in under 5-mortality varied from $6.6 \%$ in Nepal to $-0.9 \%$ in Kenya, with six of the 19 African countries all experiencing less than a $1 \%$ decline in mortality. The strongest correlation with reductions in U5MR was observed for access to clinical services (all countries: $p=0.02, r^{2}=0.58$; 19 African countries $p<0.001, r^{2}=0.67$ ). For outreach activities, AAC U5MR was significantly correlated with antenatal care and family planning services, while AAC in immunization services showed no association. In the family- and community services domain, improvements in breastfeeding were associated with significant changes in mortality in the 30 countries but not in the African subset; while in the African countries, nutritional status improvements were associated with a significant decline in mortality.
\end{abstract}

Conclusions: Our findings support the importance of increasing access to clinical services, certain outreach services and breastfeeding and, in Africa, of improving nutritional status. Integrated programs that emphasize these services may lead to substantial mortality declines.

\footnotetext{
* Correspondence: nancy.binkin3@gmail.com

${ }^{1}$ Health Section, Programme Division, UNICEF, 3 UN Plaza, New York, NY,

USA

Full list of author information is available at the end of the article
} 


\section{Background}

A series of recent metanalyses have identified over 60 interventions that are effective in reducing mortality in children under five years of age [1]. Broadly speaking, they can be divided into three groups: i) interventions for direct treatment of illnesses ii) preventive interventions such as immunization and iii) health promotion/ behavioral change interventions such as breastfeeding. Coverage remains low for many of the interventions, and unless it can be accelerated, it is unlikely that the Millennium Development Goal (MDG) 4 of a two-thirds reduction in under-five mortality from 1990 by 2015 will be met at the global level [2]. Efforts have thus been intensified by UNICEF and others to assist countries in identifying the most effective packages of interventions to address their leading causes of death within the context of the country's health care system and identify the bottlenecks that would need to be overcome to achieve high coverage.

Although in fragile countries or those with minimal infrastructure there may be a role for programs delivering a limited number of interventions [3], there has been increased emphasis in recent years on the provision of broader packages that share a common delivery mechanism and/or target population (e.g., the treatment of diarrhea, pneumonia, and malaria at community or facility level or the bundling of interventions that can be delivered through periodic outreach, such as vaccination, vitamin $\mathrm{A}$, and bed net distribution) $[4,5]$. Whilst there is a large and growing evidence base regarding the composition and packaging of essential interventions, the evidence for which types of interventions should receive priority when considering marginal investments by governments and donors is unclear. A persistent concern has been that merely increasing expenditure on priority sets of interventions will not be sustainable without commensurate investments in health systems. The first step in combining a focus on critical interventions with investments in health systems is to identify the different ways in which interventions are delivered.

There are essentially three domains for the delivery of such packages, as outlined in the 2004 World Development Report [6]. The first domain is clinically-based services delivered at the individual level, which include not only treatment of such major childhood killers as diarrhea, pneumonia and malaria but also the availability of skilled attendants at delivery and emergency obstetrical care. The second consists of services that can be delivered primarily through episodic contact or outreach and include immunization, distribution of insecticide-treated bed nets for the prevention of malaria, distribution of vitamin A, and antenatal care. The final domain is community and family-oriented services that support self-care and includes activities such as information and social support for breastfeeding promotion and appropriate child nutrition. The three domains operate against a complex backdrop of the social, physical, economic, and cultural environment, which may influence the extent to which the interventions achieve their potential for change.

A recent study has demonstrated that countries which are making progress towards MDG4 have in common the scaling up of services such as family planning and immunization, which are delivered through episodic contact, while the countries making the most progress have also successfully scaled up their clinic-based services [7]. Among those working in maternal and child health, however, there has been a great deal of controversy regarding which domain represents the most appropriate and cost-effective means to reduce mortality in countries which have made poor progress. Proponents of community-based services have argued that strengthening this approach presents a much quicker and pragmatic approach than the longer and more expensive building of clinic-based services in settings with existing low levels of coverage and health system infrastructure [8].

Many countries have undergone rapid changes in the three service domains and also in contextual factors such as female literacy and wealth. However the extent to which changes in these domains have had an impact on under-five mortality rates is not known. In this paper, we use data from sequential Demographic and Health Surveys (DHS) from 27 countries to examine the relationship between progress in the three service domains and average annual change (AAC) in underfive mortality rates.

\section{Methods}

\section{The countries}

The analysis was limited to 27 countries in Africa, Asia, the Middle East and North Africa, and Latin America and the Caribbean that 1) were among the 68 so-called "Countdown" countries with the highest burden of maternal and child deaths [2] and 2) had two sequential surveys with data available and of reasonable quality on a wide range of indicators. These countries included Benin, Burkina Faso, Cameroon, Chad, Eritrea, Ethiopia, Ghana, Guinea, Kenya, Madagascar, Mali, Malawi, Mozambique, Niger, Rwanda, Senegal, Tanzania, Uganda, and Zambia in Africa, Cambodia, India, and Nepal, and the Philippines in Asia, Egypt and Morocco in the Middle East and North Africa, and Bolivia and Haiti in Latin America and the Caribbean. 
Table 1 Categorization of variables

\begin{tabular}{|c|c|c|c|}
\hline Outreach services & Clinical services & Community/family services & Contextual factors \\
\hline$\overline{B C G}$ vaccination & Delivered by skilled birth attendant & Underweight & TV at home \\
\hline DTP3 vaccination & Delivered in health facility & Stunting & Electricity at home \\
\hline Measles vaccination & Delivered by a doctor & Wasting & $\begin{array}{l}\text { Education of women 15-19 } \\
\text { years }\end{array}$ \\
\hline Maternal tetanus vaccination & Delivered by C-section & $\begin{array}{l}\text { Exclusive breastfeeding for } 6 \\
\text { months }\end{array}$ & Sanitation \\
\hline Fully vaccinated & Sought care for ARI symptoms & $\begin{array}{l}\text { Breastfeeding within an hour } \\
\text { of birth }\end{array}$ & Water supply \\
\hline Possesses vaccine card & $\begin{array}{l}\text { Diarrhea episode treated with oral } \\
\text { rehydration }\end{array}$ & Total fertility rate & Gross domestic product \\
\hline At least 4 antenatal care visits & therapy or recommended home fluids & Availability of toilet & Adult HIV prevalence \\
\hline \multicolumn{4}{|l|}{ At least 1 antenatal care visit } \\
\hline $\begin{array}{l}\text { Family planning needs satisfied among } \\
\text { married women }\end{array}$ & & & \\
\hline
\end{tabular}

\section{The database and variables}

For each of the 27 countries, data were abstracted on the under-five mortality rate/1000 live births data from the most recent and penultimate DHS surveys. Data on 22 variables that individually correlated with under 5 mortality and were indicators of various types of coverage or of contextual factors were abstracted from the same the DHS country reports for each survey [9]. As shown in Table 1, outreach interventions included nine immunization and antenatal care variables as well as the proportion of family planning demand met. The seven clinical service-based interventions were related to delivery services such as skilled birth attendant and C-section coverage, although they also included treatment for diarrhea and care-seeking for pneumonia symptoms. Community and family services included feeding practices, lack of toilets, nutritional status and total fertility patterns. In addition, seven contextual variables known to be associated with overall mortality such as female literacy, water and sanitation, household goods, gross domestic product, and adult HIV prevalence were also included. All but gross domestic product (GDP) data and HIV prevalence were obtained from the DHS reports, while GDP was obtained from the World Bank [10], and HIV prevalence among adults 15-49 years of age was abstracted from UNAIDS country-specific projections [11]. In the case of GDP and HIV data, the information abstracted was for the same years in which the most recent and penultimate DHS surveys had been conducted. Under-five mortality rates were based on the values obtained from the openly available Child Mortality Estimates electronic database (CME info) [12].

For each country, AAC in under-five mortality rates was calculated as follows:

In $\left(x_{1} / x_{0}\right) / y e a r s$, where $x_{1}$ was the value from the most recent survey, $x_{0}$ from the penultimate survey, and years was the number of years between the two surveys.
Similarly, the AAC was calculated for each of the service and contextual variables.

\section{Statistical analysis}

The 22 indicators in the outreach, clinical and community services domains were reduced to a smaller number of elements using principal component analysis (PCA), a multivariate statistical technique used to reduce the number of variables in a data set into a smaller number of dimensions [13]. In this method, correlated variables are grouped together and PCA creates uncorrelated indices or components, whereby each component is a linear weighted combination of the initial variables. The weights for each principal component are given by the eigenvectors using the correlation matrix. Components from outreach, clinical and community services with eigenvalues > 1 were extracted on the basis of the scree plot, the percentage of variation explained in the total data and evaluation of the factor loading matrix after orthogonal (varimax) rotation [13]. The factor loadings, shown in Table 2, reflected the contribution and direction of correlation between each variable and the component.

To provide an indication of the magnitude of the actual changes for each of the 9 identified components, the AAC for each indicator within the component was summed and divided by the number of indictors within the component for the 27 countries.

Linear regression was used to examine the relationships between the outcome variable (AAC in under-5 mortality between the most recent and penultimate DHS surveys) and explanatory variables (AAC in each outreach, clinical and family- and community-based component). This method estimates how much the value of the outcome changes when the values of the explanatory variable changes by one unit. In each linear regression model, we determined the robust standard error to control for heteroskedasticity. The amount of 
Table 2 Results of the principal component analysis describing factor loadings for each component in outreach, clinical and community services in all countries $(n=27)$

\begin{tabular}{|c|c|c|c|c|c|c|c|}
\hline \multirow[t]{2}{*}{ Variables (V) } & \multicolumn{3}{|c|}{ Outreach services } & \multicolumn{2}{|c|}{ Clinical services } & \multicolumn{2}{|c|}{ Community/ family services } \\
\hline & $\begin{array}{l}\text { Component } \\
1\end{array}$ & $\begin{array}{l}\text { Component } \\
2\end{array}$ & $\begin{array}{l}\text { Component } \\
3\end{array}$ & $\begin{array}{l}\text { Component } \\
1\end{array}$ & $\begin{array}{l}\text { Component } \\
2\end{array}$ & $\begin{array}{l}\text { Component } \\
1\end{array}$ & $\begin{array}{l}\text { Component } \\
2\end{array}$ \\
\hline Measles vaccination & 0.4246 & 0.0208 & 0.0165 & & & & \\
\hline DTP3 vaccination & 0.4393 & -0.0066 & -0.0037 & & & & \\
\hline BCG vaccination & 0.4217 & -0.0208 & 0.0291 & & & & \\
\hline Fully vaccinated & 0.4431 & -0.0037 & 0.0164 & & & & \\
\hline Tetanus & 0.4177 & -0.1288 & -0.1382 & & & & \\
\hline Vaccination card & 0.2770 & 0.2731 & 0.0988 & & & & \\
\hline At least four antenatal visits & -0.0359 & 0.7027 & -0.1839 & & & & \\
\hline At least one antenatal visit & 0.0122 & 0.6432 & 0.1615 & & & & \\
\hline Family planning services & -0.0033 & -0.0201 & 0.9539 & & & & \\
\hline Proportion (\%) & 0.52 & 0.21 & 0.12 & & & & \\
\hline Cumulative variance (\%) & 0.52 & 0.73 & 0.85 & & & & \\
\hline Attended by a doctor at delivery & & & & 0.4326 & -0.1232 & & \\
\hline Access to a skilled birth attendant & & & & 0.5105 & 0.0896 & & \\
\hline Institutional delivery & & & & 0.5610 & -0.0424 & & \\
\hline C-section & & & & 0.4775 & 0.0560 & & \\
\hline Treatment for pneumonia & & & & 0.0732 & 0.6880 & & \\
\hline Treatment for diarrhea & & & & -0.0648 & 0.7060 & & \\
\hline Proportion (\%) & & & & 0.49 & 0.24 & & \\
\hline Cumulative variance (\%) & & & & 0.49 & 0.73 & & \\
\hline Underweight & & & & & & 0.5457 & 0.2679 \\
\hline Stunting & & & & & & 0.6132 & -0.1164 \\
\hline Wasting & & & & & & 0.5872 & 0.0303 \\
\hline Total fertility rate & & & & & & 0.4759 & -0.1285 \\
\hline $\begin{array}{l}\text { Exclusive breastfeeding for } 6 \\
\text { months }\end{array}$ & & & & & & -0.2402 & 0.5521 \\
\hline $\begin{array}{l}\text { Breastfeeding within an hour of } \\
\text { birth }\end{array}$ & & & & & & 0.2030 & 0.4985 \\
\hline Toilet & & & & & & 0.2658 & -0.3840 \\
\hline Proportion (\%) & & & & & & 0.32 & 0.29 \\
\hline Cumulative variance (\%) & & & & & & 0.32 & 0.61 \\
\hline
\end{tabular}

variance of the outcome explained by each predictor variable was estimated by $\mathrm{R}$-square $\left(\mathrm{r}^{2}\right)$. All estimates were adjusted for the confounding potential of contextual factors (displayed in table 1. They were also adjusted for the under-five mortality rates at baseline (the penultimate survey) as a means of increasing the comparability at the starting point of the 27 countries. All analyses were performed using Stata Version 11 (Stata Corp, TX, USA).

Because the influence of the three domains and contextual factors may vary in different settings, we performed parallel additional analyses for a subset of the 19 African countries in our study.

\section{Results}

Under-five mortality rates and average annual change (AAC) As shown in Table 3, under-5 mortality in the penultimate surveys, conducted between 1992 and 2001, ranged from 60/1000 live births in the Philippines to 274/1000 in Niger. Values from the most recent surveys, which took place between 2002 and 2006, ranged from 37/ 1000 in the Philippines to 206/1000 in Chad. AAC in under 5-mortality also varied widely, from $6.6 \%$ in Nepal to $-0.9 \%$ in Kenya, with six African countries all experiencing less than a $1 \%$ decline in mortality.

\section{Results of the principal component analysis}

Results of the PCA for the 27 countries, including the factor loadings and the total variance explained, are shown in Table 2. The first PCA on outreach services reduced the nine variables to three components that explained $85 \%$ of the total variance: 1 ) immunization (BCG, measles, DTP3, maternal tetanus vaccination; fully vaccinated; and has vaccine card); 2) antenatal care ( $\geq 1$ and $\geq 4$ antenatal care visits) and 3 ) family planning (family planning need satisfied among married women). 
Table 3 Year of most recent survey, years since penultimate survey, mortality rates and average annual change in under- 5 mortality

\begin{tabular}{|c|c|c|c|c|c|}
\hline \multirow[b]{2}{*}{ Country } & \multirow[b]{2}{*}{$\begin{array}{c}\text { year of } \\
\text { most } \\
\text { recent } \\
\text { survey }\end{array}$} & \multirow[b]{2}{*}{$\begin{array}{c}\text { Years } \\
\text { since last } \\
\text { survey }\end{array}$} & \multicolumn{2}{|c|}{$\begin{array}{l}\text { Under } 5 \text { mortality } \\
\text { rate/1000 live births }\end{array}$} & \multirow[b]{2}{*}{ U5MR } \\
\hline & & & $\begin{array}{l}\text { penultimate } \\
\text { survey }\end{array}$ & $\begin{array}{l}\text { most } \\
\text { recent } \\
\text { survey }\end{array}$ & \\
\hline Benin & 2006 & 5.0 & 148 & 132 & $2.3 \%$ \\
\hline Bolivia & 2003 & 9.5 & 121 & 82 & $4.1 \%$ \\
\hline Burkina Faso & 2003 & 10.5 & 206 & 190 & $0.8 \%$ \\
\hline Cambodia & 2005 & 5.5 & 118 & 93 & $4.3 \%$ \\
\hline Cameroon & 2004 & 6.0 & 151 & 144 & $0.8 \%$ \\
\hline Chad & 2004 & 7.0 & 201 & 206 & $-0.4 \%$ \\
\hline Egypt & 2005 & 9.0 & 78 & 45 & $6.1 \%$ \\
\hline Eritrea & 2002 & 7.0 & 133 & 99 & $4.2 \%$ \\
\hline Ethiopia & 2005 & 5.0 & 167 & 138 & $3.8 \%$ \\
\hline Ghana & 2003 & 4.7 & 111 & 111 & $0.0 \%$ \\
\hline Guinea & 2005 & 6.0 & 204 & 175 & $2.6 \%$ \\
\hline Haiti & 2005 & 11.0 & 151 & 93 & $4.4 \%$ \\
\hline India & 2006 & 7.0 & 103 & 81 & $3.5 \%$ \\
\hline Kenya & 2003 & 5.0 & 111 & 116 & $-0.9 \%$ \\
\hline Madagascar & 2004 & 6.3 & 156 & 132 & $2.7 \%$ \\
\hline Malawi & 2004 & 4.0 & 192 & 152 & $5.8 \%$ \\
\hline Mali & 2006 & 5.5 & 229 & 201 & $2.4 \%$ \\
\hline Morocco & 2004 & 11.5 & 93 & 51 & $5.2 \%$ \\
\hline Mozambique & 2003 & 6.5 & 212 & 163 & $4.0 \%$ \\
\hline Nepal & 2006 & 5.0 & 96 & 69 & $6.6 \%$ \\
\hline Niger & 2006 & 8.0 & 274 & 204 & $3.7 \%$ \\
\hline Philippines & 2003 & 10.0 & 60 & 37 & $4.8 \%$ \\
\hline Rwanda & 2005 & 5.0 & 200 & 180 & $2.1 \%$ \\
\hline Senegal & 2005 & 8.0 & 148 & 125 & $2.2 \%$ \\
\hline Tanzania & 2004 & 8.0 & 156 & 131 & $2.2 \%$ \\
\hline Uganda & 2006 & 5.5 & 155 & 138 & $2.1 \%$ \\
\hline Zambia & 2002 & 5.5 & 178 & 178 & $0.0 \%$ \\
\hline
\end{tabular}

PCA was also used for item reduction of the six variables on clinical services to two components that explain $73 \%$ of the total variance: 1 ) access to services (physician as birth attendant, skilled birth attendant, institutional delivery, and Cesarean section); 2) seeking treatment (care-seeking for pneumonia and appropriate diarrhea treatment). The third PCA on community and family services reduced the seven variables to two components that explain $61 \%$ of the total variance: 1 ) nutritional status (underweight, stunting, and wasting) and 2) breastfeeding (breastfeeding within an hour of birth and exclusive breastfeeding for the first six months of life). The former component also included total fertility rate and the latter absence of toilet. We restricted the PCA analyses to the 19 African countries and found similar results (components) for outreach services (84\% of variance explained), clinical services (69\% of variance explained) and community and family services (67\% of variance explained).

\section{Average annual change in outreach, clinical, and community and family components}

The average of the AAC for each indicator in the nine domains is shown in Table 4. Of note are the wide variations in AAC for many of the components between countries, the limited magnitude of the changes in many of the countries, and the negative AAC for several components, especially in some of the African countries.

\section{Correlation between AAC in outreach components and $A A C$ in under-five mortality}

The results of the linear regression analyses for all countries showed that an increase in antenatal $\left(\mathrm{p}=0.006, \mathrm{r}^{2}\right.$ $=0.38)$ and family planning $\left(\mathrm{p}=0.02, \mathrm{r}^{2}=0.32\right)$ services delivery through outreach or episodic activities was correlated with a decline in under-five mortality rates (Table 5). In the 19 African countries, changes in antenatal services was the only component that was correlated to a decrease in under-five mortality rates $(\mathrm{p}=$ $0.04, r^{2}=0.29$ ) (Table 6). Overall, the analyses showed poor correlation for immunization services.

\section{Correlation between AAC in clinical components and AAC} in under-five mortality

As shown in Tables 5 and 6, change in access to clinical services for delivery demonstrated the strongest correlation with declines in under-five mortality for all countries $\left(\mathrm{p}=0.02, \mathrm{r}^{2}=0.58\right)$ and for the 19 African countries $\left(\mathrm{p}<0.001, \mathrm{r}^{2}=0.67\right)$. AAC in care seeking treatment for pneumonia and diarrhea was correlated with change in under-five mortality for all 27 countries, but the association was weaker and non-significant for the subset of African countries (Table 6).

\section{Correlation between AAC in community and family components and $A A C$ in under-five mortality}

A moderate correlation was noted for the breastfeeding component when the analyses included all countries ( $\mathrm{p}$ $\left.=0.006, r^{2}=0.38\right)$ (Table 5), but a weaker and non-significant association was observed for the 19 African countries. By contrast, for the 19 African countries (Table 6), an improvements in childhood nutritional status were significantly correlated to a decline in underfive mortality rates $\left(\mathrm{p}=0.01, \mathrm{r}^{2}=0.40\right)$, while the relationship was weaker and non-significant for the full set of 27 countries.

\section{Discussion}

Our study demonstrated considerable variability in the $\mathrm{AAC}$ in under-five mortality among the 27 countries and that the strongest predictor of changes in under-five 
Table 4 AAC in components of outreach, clinical, and community and family services

\begin{tabular}{|c|c|c|c|c|c|c|c|}
\hline \multirow[b]{2}{*}{ Country } & \multicolumn{3}{|c|}{ Outreach services } & \multicolumn{2}{|r|}{ Clinical services } & \multicolumn{2}{|c|}{ Community Services } \\
\hline & Immunization & Antenatal care & Family planning & Access & Careseeking/ treatment & Nutrition & Breastfeeding \\
\hline Benin & $-0.1 \%$ & $-0.1 \%$ & $-2.2 \%$ & $0.9 \%$ & $-1.1 \%$ & $-0.9 \%$ & $4.1 \%$ \\
\hline Bolivia & $4.0 \%$ & $5.1 \%$ & $0.6 \%$ & $3.5 \%$ & $1.1 \%$ & $4.6 \%$ & $4.9 \%$ \\
\hline Burkina Faso & $1.1 \%$ & $-0.1 \%$ & $0.2 \%$ & $-1.8 \%$ & $4.2 \%$ & $-1.3 \%$ & $7.7 \%$ \\
\hline Cambodia & $8.1 \%$ & $15.5 \%$ & $6.8 \%$ & $13.5 \%$ & $1.8 \%$ & $5.7 \%$ & $17.1 \%$ \\
\hline Cameroon & $3.1 \%$ & $1.6 \%$ & $-1.0 \%$ & $-0.8 \%$ & $-0.6 \%$ & $0.0 \%$ & $2.9 \%$ \\
\hline Chad & $0.3 \%$ & $4.9 \%$ & $-15.1 \%$ & $0.8 \%$ & $-6.7 \%$ & $0.3 \%$ & $2.4 \%$ \\
\hline Egypt & $1.0 \%$ & $7.3 \%$ & $1.4 \%$ & $7.7 \%$ & $-1.8 \%$ & $4.1 \%$ & $-0.7 \%$ \\
\hline Eritrea & $7.4 \%$ & $5.7 \%$ & $0.3 \%$ & $5.5 \%$ & $2.9 \%$ & $2.2 \%$ & $2.3 \%$ \\
\hline Ethiopia & $7.1 \%$ & $1.9 \%$ & $9.8 \%$ & $3.5 \%$ & $-0.2 \%$ & $1.6 \%$ & $4.8 \%$ \\
\hline Ghana & $1.7 \%$ & $1.6 \%$ & $1.5 \%$ & $-0.7 \%$ & $4.8 \%$ & $1.4 \%$ & $8.6 \%$ \\
\hline Guinea & $1.2 \%$ & $1.7 \%$ & $6.3 \%$ & $-0.1 \%$ & $-1.1 \%$ & $-1.9 \%$ & $8.0 \%$ \\
\hline Haiti & $2.4 \%$ & $2.9 \%$ & $4.3 \%$ & $3.3 \%$ & $2.7 \%$ & $1.3 \%$ & $4.2 \%$ \\
\hline India & $1.7 \%$ & $3.1 \%$ & $1.1 \%$ & $2.5 \%$ & $0.3 \%$ & $0.2 \%$ & $3.9 \%$ \\
\hline Kenya & $-1.5 \%$ & $-2.0 \%$ & $0.0 \%$ & $-3.2 \%$ & $-4.8 \%$ & $1.2 \%$ & $-0.4 \%$ \\
\hline Madagascar & $3.5 \%$ & $0.4 \%$ & $3.4 \%$ & $0.6 \%$ & $1.2 \%$ & $-1.8 \%$ & $7.1 \%$ \\
\hline Malawi & $-0.9 \%$ & $0.3 \%$ & $2.1 \%$ & $2.0 \%$ & $5.4 \%$ & $1.7 \%$ & $1.9 \%$ \\
\hline Mali & $7.1 \%$ & $3.4 \%$ & $-1.0 \%$ & $3.2 \%$ & $-2.0 \%$ & $-0.1 \%$ & $5.3 \%$ \\
\hline Morocco & $-0.7 \%$ & $7.3 \%$ & $1.9 \%$ & $7.9 \%$ & $3.4 \%$ & $-2.5 \%$ & $-0.6 \%$ \\
\hline Mozambique & $4.6 \%$ & $4.0 \%$ & $5.7 \%$ & $1.2 \%$ & $3.8 \%$ & $1.5 \%$ & $0.0 \%$ \\
\hline Nepal & $6.1 \%$ & $11.7 \%$ & $2.4 \%$ & $13.4 \%$ & $3.7 \%$ & $0.5 \%$ & $2.0 \%$ \\
\hline Niger & $4.3 \%$ & $2.7 \%$ & $2.9 \%$ & $3.1 \%$ & $2.4 \%$ & $1.8 \%$ & $15.6 \%$ \\
\hline Philippines & $-0.2 \%$ & $1.8 \%$ & $1.9 \%$ & $2.1 \%$ & $1.9 \%$ & $1.5 \%$ & $2.8 \%$ \\
\hline Rwanda & $-0.6 \%$ & $2.7 \%$ & $2.9 \%$ & $-0.1 \%$ & $6.4 \%$ & $2.6 \%$ & $-0.2 \%$ \\
\hline Senegal & $2.5 \%$ & $5.9 \%$ & $0.0 \%$ & $1.1 \%$ & $1.6 \%$ & $1.7 \%$ & $7.3 \%$ \\
\hline Tanzania & $-0.8 \%$ & $2.1 \%$ & $3.3 \%$ & $2.1 \%$ & $-1.3 \%$ & $4.3 \%$ & $2.0 \%$ \\
\hline Uganda & $4.4 \%$ & $1.2 \%$ & $-1.3 \%$ & $3.0 \%$ & $0.9 \%$ & $0.4 \%$ & $-1.7 \%$ \\
\hline Zambia & $-2.1 \%$ & $-0.2 \%$ & $2.1 \%$ & $-1.1 \%$ & $-1.3 \%$ & $-1.9 \%$ & $4.2 \%$ \\
\hline
\end{tabular}

Values represent the average of the AAC for each indicator within the component.

Table 5 Linear regression analysis examining the correlation between average annual change in under- 5 mortality rates and average annual change in each component within outreach, clinical and community services in all countries $(\mathbf{n}=\mathbf{2 7})$

\begin{tabular}{|c|c|c|c|c|}
\hline Component & Coefficient & 95\% Confidence interval & p value* & $r^{2}+$ \\
\hline \multicolumn{5}{|l|}{ Outreach services } \\
\hline Component 1: Immunization & 0.0032 & $-0.0004,0.0069$ & 0.08 & 0.09 \\
\hline Component 2: antenatal care & 0.0091 & $0.0029,0.0152$ & 0.006 & 0.38 \\
\hline Component 3: family planning & 0.0090 & $0.0017,0.0163$ & 0.018 & 0.32 \\
\hline \multicolumn{5}{|l|}{ Clinical services } \\
\hline Component 1: access to services & 0.0091 & $0.0052,0.0129$ & 0.018 & 0.58 \\
\hline Component 2: seeking treatment & 0.0074 & $0.0012,0.0136$ & 0.021 & 0.31 \\
\hline \multicolumn{5}{|l|}{ Community/ family services } \\
\hline Component 1: Nutritional issues & 0.0019 & $-0.0081,0.0042$ & 0.52 & 0.14 \\
\hline Component 2: breastfeeding & 0.0087 & $0.0028,0.0186$ & 0.006 & 0.38 \\
\hline
\end{tabular}

*p value: significance of the correlation between the AAC in each component in specific interventions and the AAC in under-5 mortality rate $+r^{2}$ is the proportion of variability in the AAC in under- 5 mortality rate that can be explained by changes in the values of each component Note: All analyses were adjusted for AAC in GDP, adult HIV prevalence, household TV and electricity, education of women 15-19, sanitation, after supply, and for under-5 mortality rate during the penultimate survey 
Table 6 Linear regression analysis examining the correlation between average annual change in under-5 mortality rates and average annual change in each component within outreach, clinical and community services in African countries $(n=19)$

\begin{tabular}{|c|c|c|c|c|}
\hline Component & Coefficient & 95\% Confidence interval & p value* & $r^{2}+$ \\
\hline \multicolumn{5}{|l|}{ Outreach services } \\
\hline Component 1: Immunization & 0.0025 & $-0.0030,0.0081$ & 0.33 & 0.10 \\
\hline Component 2: antenatal care & 0.0111 & $0.0006,0.0216$ & 0.039 & 0.29 \\
\hline Component 3: family planning & 0.0060 & $-0.0049,0.0170$ & 0.25 & 0.12 \\
\hline \multicolumn{5}{|l|}{ Clinical services } \\
\hline Component 1: access to services & 0.0118 & $0.0068,0.0167$ & 0.000 & 0.67 \\
\hline Component 2: seeking treatment & 0.0064 & $-0.0017,0.0146$ & 0.116 & 0.19 \\
\hline \multicolumn{5}{|l|}{ Community/ family services } \\
\hline Component 1: Nutritional issues & 0.0110 & $0.030,0.0190$ & 0.01 & 0.40 \\
\hline Component 2: breastfeeding & 0.0058 & $-0.0023,0.0139$ & 0.17 & 0.15 \\
\hline
\end{tabular}

${ }^{*} p$ value: significance of the correlation between the AAC in each component in specific interventions and the AAC in under-5 mortality rate $+r^{2}$ is the proportion of variability in the AAC in under- 5 mortality rate that can be explained by changes in the values of each component Note: All analyses were adjusted for AAC in GDP, adult HIV prevalence, household TV and electricity, education of women 15-19, sanitation, after supply, and for under-5 mortality rate during the penultimate survey

mortality rates was improvements in access to and coverage of clinical services. In addition, improvements in selected outreach interventions were also correlated with changes in mortality, but the effect was not as strong as for clinical services. For community and family services, we found that an improvement in breastfeeding practices/hygiene was significantly correlated with under-five mortality but that the effect was weaker and not statistically significant among the African countries. By contrast, childhood nutritional status was strongly correlated to a positive impact in under-five mortality rates only in the 19 African countries.

The importance of access to clinical services is not completely surprising as the major causes of child deaths such as pneumonia, diarrhea, malaria and various conditions of the neonatal period historically have required access to clinical services provided through health facilities. Our findings are also in keeping with those of Rohde et al [7], who demonstrated that the countries that had made the most progress as measured by average annual reduction of mortality were those which had higher coverage of comprehensive primary health care, which in their study was measured by a high prevalence of skilled attendants at birth. They, too, suggest that countries can achieve progress in child mortality even in the absence of improvements in contextual factors such as per capita income and HIV prevalence.

The observed correlation between the changes in antenatal care and family planning outreach services and mortality, though weaker than that observed for access to clinical services, suggests that improvements in access to these services can also have an important impact on mortality. With respect to immunization, some studies have reported a positive effect of immunization on child mortality [14-16], while others failed to demonstrate its effect on mortality [17-19]. Indeed, in our study, annual increases in immunization coverage were not correlated with changes in under-five mortality rates, although clearly it is essential to maintain or improve such coverage. Furthermore, the anticipated addition of pneumococcal and rotavirus vaccines to many national immunization programs may well boost the impact of improved immunization coverage on mortality.

With respect to community and family services, improved breastfeeding coverage and an increase in households with improved sanitary facilities also had an impact on under-5 mortality, although the impact was less in Africa than in the 27 countries as a whole. Indeed, exclusive breastfeeding for 6 months has been identified as having the greatest potential impact of any single intervention on under-5 mortality [20]. Regarding nutritional status, malnourished children are known to be at an increased risk of death [21-23], and it has been estimated that malnutrition contributes to about onethird of the child deaths that occur each year [24]. Our study demonstrated that an improvement in childhood nutritional status is associated with a decline in under-5 mortality rates, although the difference was significant only in the subgroup of African countries. These findings are compatible with previous studies $[23,25,26]$. It has been estimated that implementing interventions that improve child nutrition as well as provide clean water and sanitation to all children younger than 5 years would result in an estimated $31 \%$ reduction in child deaths in sub-Saharan Africa [25].

While these findings support further scaling up services in the outreach and community and family domains, they also would appear to underline the importance of additional investment in access to 
services. Prior efforts to scale up of clinical services have demonstrated major challenges in identifying and training adequate skilled staff to provide these services and in providing the facilities and logistics to ensure quality and continuity. In addition, the high costs of delivering such services have been a major inhibitory factor. Indeed, the overall costs of improving and sustaining a system capable of delivering rapid gains in health improvement are large, estimated at \$36-45 billion annually above and beyond current expenditures, and the difficulty of raising such funds given current worldwide economic conditions, is substantial [27]. At the same time, however, our findings suggest that the benefits of such improvements may also be large.

One of the reasons behind the high costs of clinical services is the difficulty of providing care to those most in need, many of whom live in remote areas where access may be difficult. An encouraging development that may improve clinical coverage and also offers some excellent opportunities for synergy with outreach and family and community efforts is integrated community case management (iCCM) [28]. In iCCM, treatment for conditions such as pneumonia diarrhea, and malaria, which account for approximately $40 \%$ of under- 5 mortality worldwide [29], is delivered at community level by specially trained community health workers. Such efforts also have the advantage of emphasizing family and community-based prevention and promotion and provide opportunities to promote better coverage of outreach services, resulting an excellent opportunity for synergy of those interventions which appear to have the greatest impact on reductions in mortality.

While other analyses have focused on the relationship between prevalence or coverage of risk factors and current mortality levels in study populations or at country level [[7]30], to our knowledge, this is the first analysis that examined the correlation between changes in individual and composite variables and changes in under-5 mortality at country level. We believe this approach provides a more dynamic way of examining how the scaling up of different types of interventions effect changes in under- 5 mortality rates that is not provided by the simple correlation of existing coverage and mortality levels.

At the same time, however, these findings need to be interpreted cautiously. First, the results may not be generalizable because of the limited number of countries included in the analysis. We believe, however, that the countries included represent a wide range of experiences, both in terms of geography and initial levels of development. A second limitation is that consistent data on potentially important variables such as vitamin A administration and use of insecticide treated bed nets, which are highly effective in preventing malaria, were not available from the penultimate surveys. Furthermore, it is clear that many of the variables we included were markers rather than directly associated with child mortality as an outcome. For example, changes in Cesarean section, which as an individual variable produced one of the highest correlations with under- 5 mortality change, was less strongly associated with reductions in the infant mortality, as might have been expected with a more direct effect; which strongly suggests that it is a marker of access to quality clinical services. A fourth limitation was that some of the variables that might be more plausibly linked to mortality such as treatment for acute respiratory infection could not be included because the twoweek reference frame in the questionnaire results in prevalence values of $<5 \%$, making calculation of average annual change problematic. A fifth limitation concerns the assumption that the effects of individual interventions and their interactions will be similar for our countries, which may not be true as suggested by the differences observed between the overall set of countries and the African countries. Finally, mortality data collected in surveys reflect events occurring in the population an average of 2.5 years previously. The mortality figures we used thus reflect mortality that occurred in the early 2000s, before many of the interventions had been scaled up, which may underestimate the influence that changes in coverage have had on mortality.

Our study looked at change rather than absolute coverage levels. It is important to keep in mind that coverage was low for many of the indicators. Except for the immunization variables, where coverage tended to be high, it was much lower for many other potentially lifesaving interventions. For example, the percentage of women reporting the use of a skilled birth attendant ranged from $6 \%$ to $83 \%$, with a median value of $47 \%$ for the 27 countries; for appropriate treatment of diarrhea, values ranged from a low of $18 \%$ to a high of $75 \%$, with a median of $37 \%$. These data suggest that there is great room for improvement, even in countries that have already made substantial progress.

\section{Conclusions}

Although this study is limited by its ecologic nature and the limited number of countries and information that were available for inclusion, we nonetheless feel that the method of examining average annual change rather than looking at absolute levels of outcomes should be considered in future studies examining the impact of change at a population level. More importantly, however, the findings on the apparent role of clinical services in further reducing under-five mortality may provide support to current efforts to improve the availability of care at community level and to make needed improvements in the health infrastructure, manpower, and logistic and supply systems. 


\section{Acknowledgements and funding}

The authors wish to thank David Brown and Attila Hancioglu for their helpful comments and suggestions, to Mary Gray and David Olsen for their invaluable advice on data analysis, and Danielle Burke and Carlos Carrera for their assistance in identification of data bases used in these analyses. No specific funding was provided for this project, which was considered a routine UNICEF activity.

\section{Abbreviations}

AAC: Average annual change; DHS: Demographic and Health Surveys; GDP: Gross domestic product; iCCM: Integrated community case management; MDG: Millennium Development Goals; PCA: Principal component analysis; UNICEF: United Nations Children's Fund

\section{Author details}

'Health Section, Programme Division, UNICEF, 3 UN Plaza, New York, NY, USA. ${ }^{2}$ UNICEF Country Office, Yerevan, Armenia. ${ }^{3}$ D336 Defence Colony, Delhi, India.

\section{Authors' contributions}

NB contributed to the conception, analysis, and writing of the article. MC contributed to the conceptual framework and writing. ASK performed the statistical analyses and contributed to the writing. DW contributed to the conception, developed the data-base, and provided input into the analysis and writing. All authors approved the final manuscript.

\section{Competing interests}

The authors declare that they have no competing interests.

Received: 12 October 2010 Accepted: 9 June 2011

Published: 9 June 2011

\section{References}

1. Walker N, ed: Development and use of the Lives Saved Tool (LiST): A model to estimate the impact of scaling up proven interventions on maternal, neonatal and child mortality. Int J Epidemiol 2010 39(supplement 1)

2. Countdown to 2015: Countdown to 2015 decade report (2000-2010): taking stock of maternal, newborn and child survival. WHO and UNICEF. 2010 [http://www.countdown2015mnch.org/reports-publications/2010report].

3. Victora CG, Hanson K, Bryce J, Vaughan JP: Achieving universal coverage with health interventions. Lancet 2004, 364:1541-1548.

4. Kerber K, de Graft-Johnson JE, Bhutta ZA, Okong P, Starrs A, Lawn JE: Continuum of care for maternal, newborn, and child health: from slogan to service delivery. The Lancet 2007, 370:1358-1369.

5. Doherty T, Chopra M, Tomlinson M, Oliphant N, Nsibande D, Mason J: Moving from vertical to integrated child health programmes: experiences from a multi-country assessment of the Child Health Days approach in Africa. Trop Med Int Health 2010, 15:296-305.

6. World Bank. World Development Report 2004: Making Services Work for Poor People. Washington, D.C. Washington (DC)7 The World Bank Group; 2004.

7. Rohde J, Cousens S, Chopra M, et al: $\mathbf{3 0}$ years after Alma-Ata: has primary health care worked in countries? Lancet 2008, 372:950-61.

8. Kinney MV, Kerber KJ, Black RE, Cohen B, Nkrumah F, Coovadia H, Nampala PM, Lawn JE, Science in Action: Saving the lives of Africa's Mothers, Newborns, and Children working group, Axelson H, Bergh AM, Chopra M, Diab R, Friberg I, Odubanjo O, Walker N, Weissman E: SubSaharan Africa's mothers, newborns, and children: Where and why do they die? PLoS Med 2010, 7(6):e1000294.

9. Measure DHS Demographic and Health Surveys. [http://www.measuredhs. com].

10. World Data Bank World Development Indicators \& Global Development Finance. [http://databank.worldbank.org].
11. 2008 Report on the global AIDS epidemic. Adult (15-49) IV prevalence percent by country. 1990 [http://data.unaids.org/pub/GlobalReport/2008/ 20080813_gr08_prev1549_1990_2007_en.xls].

12. CME info. [http://www.childmortalityestimates.org].

13. Giri NC: Multivariate statistical analysis. New York: Marcel Dekker Inc; 2004.

14. Breiman RF, Streatfield PK, Phelan M, Shifa N, Rashid M, Yunus M: Effect of infant immunisation on childhood mortality in rural Bangladesh: analysis of health and demographic surveillance data. Lancet 2004, 364(9452):2204-2211.

15. Sudfeld CR, Navar AM, Halsey NA: Effectiveness of measles vaccination and vitamin A treatment. Int J Epidemiol 2010, 39(Suppl 1):i48-55.

16. Blencowe H, Lawn J, Vandelaer J, Roper M, Cousens S: Tetanus toxoid immunization to reduce mortality from neonatal tetanus. Int J Epidemiol 2010, 39(Suppl 1):1102-109.

17. Aaby P, Benn CS, Nielsen J, Lisse IM, Rodrigues A, Jensen H: DTP vaccination and child survival in observational studies with incomplete vaccination data. Trop Med Int Health 2007, 12(1):15-24.

18. Nwogu R, Larson JS, Kim MS: Reducing child mortality in Nigeria: a case study of immunization and systemic factors. Soc Sci Med 2008, 67(1):161-164

19. Roth AE, Benn CS, Ravn H, Rodrigues A, Lisse IM, Yazdanbakhsh M, Whittle $H$, Aaby P: Effect of revaccination with BCG in early childhood on mortality: randomised trial in Guinea-Bissau. BMJ 2010, 340.

20. Jones G, Steketee RW, Black RE, Bhutta ZA, Morris SS: How many child deaths can we prevent this year? Lancet 2003, 362:65-71.

21. Pelletier DL: The relationship between child anthropometry and mortality in developing countries: implications for policy, programs and future research. J Nutr 1994, 124:2047S-2081S.

22. Villamor E, Misegades L, Fataki MR, Mbise RL, Fawzi WW: Child mortality in relation to HIV infection, nutritional status, and socio-economic background. Int J Epidemiol 2005, 34:61-68.

23. Black RE, Allen LH, Bhutta ZA, Caulfield LE, de Onis M, Ezzati M, Mathers C, Rivera J, Maternal and Child Undernutrition Study Group: Maternal and child undernutrition: global and regional exposures and health consequences. Lancet 2008, 371:243-260.

24. United Nations Children's Fund: The state of the world's children 2008. New York, NY: UNICEF; 2007.

25. Gakidou E, Oza S, Vidal Fuertes C, Li AY, Lee DK, Sousa A, Hogan MC, Vander Hoorn S, Ezzati M: Improving child survival through environmental and nutritional interventions: the importance of targeting interventions toward the poor. JAMA 2007, 298(16):1876-1887.

26. Vesel L, Bahl R, Martines J, Penny M, Bhandari N, Kirkwood BR, the WHO Immunization-linked Vitamin A Supplementation Study Group: Use of new World Health Organization child growth standards to assess how infant malnutrition relates to breastfeeding and mortality. Bull World Health Organ 2010, 88:39-48.

27. Taskforce on Innovative International Financing for Health Systems: More money for health, and more health for the money. 2009 [http://www. internationalhealthpartnership.net/pdf/HP\%20Update\%2013/Taskforce/ Johansbourg/Final\%20Taskforce\%20Report.pdf], accessed 14March 2011.

28. CORE Group, Save the Children, BASICS and MCHIP: Community case management essentials: treating common childhood illnesses in the community. A guide for program managers. Washington, D.C; 2010.

29. Black RE, Cousens S, Johnson HL, Lawn JE, Rudan I, Bassani DG, Jha P, Campbell H, Walker CF, Cibulskis R, Eisele T, Liu L, Mathers C, Child Health Epidemiology Reference Group of WHO and UNICEF: Global, regional, and national causes of child mortality in 2008: a systematic analysis. Lancet 2010, 375(9730):1969-1987.

\section{Pre-publication history}

The pre-publication history for this paper can be accessed here: http://www.biomedcentral.com/1471-2458/11/456/prepub

\section{doi:10.1186/1471-2458-11-456}

Cite this article as: Binkin et al.: Do improvements in outreach, clinical, and family and community-based services predict improvements in child survival? An analysis of serial cross-sectional national surveys. BMC Public Health 2011 11:456 